\title{
Cultural context in credibility studies: A multidimensional perspective
}

\section{Hanaa Farouk saleh*}

\begin{abstract}
:
The purpose of this article was to examine the role of culture in credibility assessment and determine to what extent it was applicable to media studies. Existing quantitative research in media credibility neglects cultural dimensions in communication process. This article addresses this gap by offering a theoretical, multidimensional model of cultural and communication components that influence media credibility across and within cultures. The main consideration for future studies includes testing the model components of this paper in different contexts.
\end{abstract}

Keywords: cultural dimensions of media credibility, media credibility and culture, cultural context model.

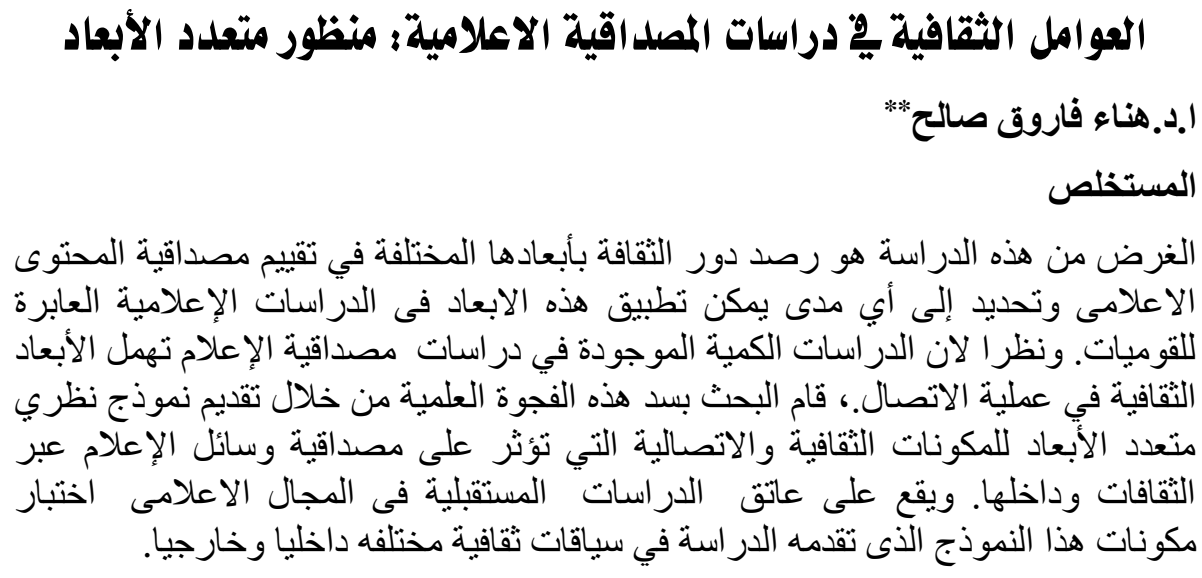

* Assistant Professor, Department of Journalism, Faculty of Mass Communication Cairo University

| استاذ مساعد بقسم الصحافة بكلية الإعلام - جامعة القاهرة 
The purpose of this article is to examine the cultural dimensions affecting media credibility evaluations and propose a cultural context credibility model between and within cultures. The existing model of credibility needed to address cultural variables to better explain media credibility process. This paper examines culture factors influencing media credibility from a cross cultural perspectives. Credibility research has dealt with sources, mediums and messages from the same country-of-origin, this article suggests a broader level of analysis: political, economic, social and cultural power dynamics between countries and within cultures as a main predictor of credibility. Most view communication context as stable, I consider media context and cultural variations as main forces affecting the perceptions of media credibility that orient audience when choosing media and make judgment about its content. Unfortunately, in searching for an instrument for cross cultural credibility dimensions, such a measure doesn't yet exist. (Wasti S.Arzu et al.2007) Thus, establishing cultural context model to measure credibility between and within societies will constitute a necessary first for doing cross culture research about media credibility. Based on existing work, a theoretical framework was developed. In this paper, first I introduce the theoretical background of this article concerning culture and media credibility; then the research model will be proposed; after that, I describe the different components of the model and explain its relation with credibility; finally, it concludes with discussion and future research orientations.

\section{Media, Culture and Credibility: A Theoretical Framework}

Culture plays a significant part in our daily life from birth to death, so human beings can't be studied without invoking cultural dimensions of human life. The current research methods treat culture as autonomous individual characteristics that are isolated from daily living and from broader social, economic, and political contexts. Researchers sometimes, assume that concepts are universal across cultural by relying on standard measures to collect data without consideration of their original developmental basis. (Kao Hsueh-fen $\mathrm{S}$ et al, 2004)

Bercovitch and Elgström offer the first systematic analysis of how cultural differences and similarities between society influence 
credibility: Similar cultures are related to common patterns of interacting and reacting to the actions of others, as well as shared values and beliefs. (Bakaki Zorzeta et al.,2015). No culture exists without orientations of credibility, and the characteristics of credibility emerge from cultural values. Even if a cultural group achieved perfect uniformity across all members, some set of cultural values would still develop as necessary to plan and maintain communicative experiences. (Lowe Susana Ming,1997)

Contemporary research regarding credibility takes a lot of elements into consideration when exploring the factors that contribute to higher credibility perceptions. Common cultural characteristics between source and receiver could be credibility assets, which influence communication occurrence and effectiveness. Links between a sources and audience generally make the transmission of information about interests and intentions more credible.( Bakaki Zorzeta et al ,2015,p7)

Research has found that source-receiver similarity plays an important role in credibility perceptions. Early research in persuasion operated under the assumption that communicators that are perceived as similar to their audiences are considered more credible, and thus, more likely to persuade. In communication research, there are three areas of study that highlight similarities as influencing factors in credibility judgments: homophile, involvement, and identification. Research has found a relationship between these factors and credibility, sometimes perceived similarities facilitate higher credibility perceptions, other results reveal that identification may result in distrust towards media. Babiker and colleagues developed an index that measured the perceived similarities between two cultures based on the following characteristics: "climate, food, language, religion, educational level, material comfort, family life, marriage and intergroup conflict". One of the most popular applications of cultural proximity is attributed to Geert Hofstede's cultural index. It involves five dimensions: individualism, power distance, uncertainty avoidance, masculinity, and Confucian dynamism. (Arora Payal,2012)

Several intercultural communication theories describe differences and similarities of self and other oriented cultural values using a dualistic style of research design to further test the construct of credibility across cultures. The self-oriented cultural values indicate an 
orientation of credibility referred to as source-credibility. The other oriented cultural values indicate an orientation of a credibility referred to as the sponsorship effect, or vicarious-credibility. (Dilbeck,Keith E.,2014)

The question addressed in this article is, to what degree media credibility evaluations are affected by culture? Its primary objective is to understand how specific cultural and environmental variations are related to individual judgments of communication credibility and to determine the main components of the proposed cultural context credibility model. The processes of globalization have led to a search for media credibility frameworks that can be applicable across cultures. Until now the bulk of scholarship devoted to the quest for universal media credibility measures has come from the West. These frameworks can't be applied to non-western contexts, and local cultures, sociopolitical issues and histories must be taken into account. (Wasserman Herman,2004). Analyzing cultural aspects requires considering the intensive interaction of cultures that is experienced these days because of the extremely dynamic development and spread of communication technologies. (Demetrovics Zsolt,2012) I propose a final working model of cultural dimensions' model of media credibility between and within societies, including all the empirical and theoretical dimensions extracted from several cultural and media studies. As previously mentioned, this paper aims to add knowledge to the existing literature regarding media credibility research, which suggest paths for future research and confirm the vital role of the qualitative approach in research progression.

\section{The model}

The proposed model is divided into two main components: the first one composed of cultural context credibility determinants between nations and the second composed of cultural context credibility determinants within cultures. Based upon past research it is hypothesized that cultural components between and within society represent a significant media credibility constructs that must be consider when developing and evaluating media credibility. These include: individualism vs. collectivism orientation, power distance, nation level, uncertainty avoidance, political regime, media systems, technology, religion and norms, economic status and timing. As for 
model components within cultures I added to previous dimensions' acculturation, group membership, social classes, women role and age.
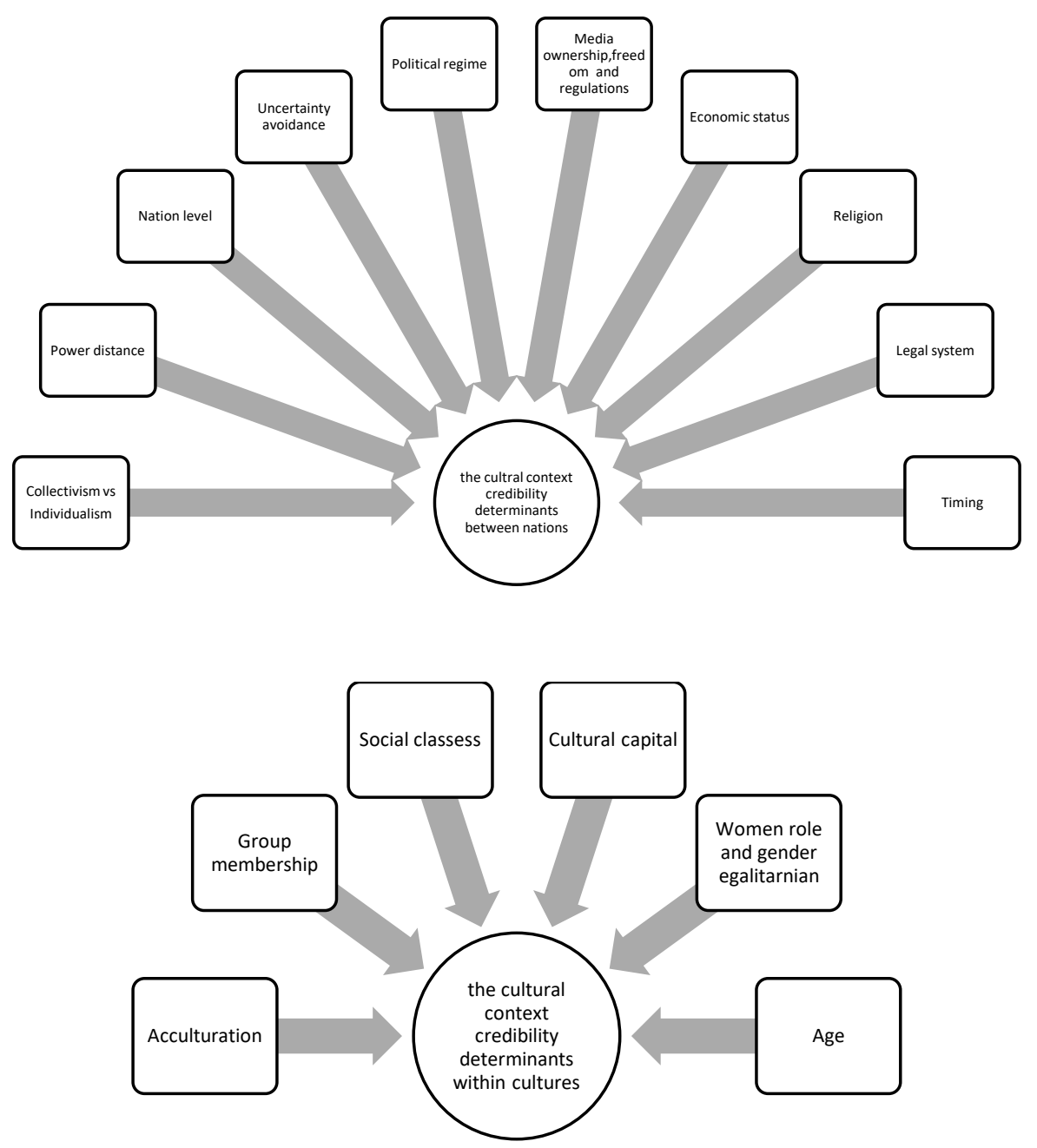

One weak point in the credibility literature is the lack of testing cultural context effects in credibility research despite its fundamental role in media effects.(Lathrop Christopher,1984) Socio-cultural context represents an important determinant in shaping media credibility across nations. Unfortunately, almost all of studies originate in the U.S. context, which reflects regime and climate where people use special criteria in judging media credibility and these criteria vary widely from country to another. Traditionally, research 
tended to treat national and cultural concerns equally, which carries some risks. In addition to the traditional heterogeneity existing for centuries in the world, the migration of different ethnic groups occurring during the past decades appears to carry considerably different cultural elements. (Demetrovics, Zsolt,2012, p16) So the main purpose of this article is to investigate the effects of culture dimensions on media credibility, and to propose a model determining different cultural components which guide future cross culture studies in media credibility. Between-groups differences exist on these variables and there would be within-group differences which in turn influence degree of media credibility.

\section{The Cultural context credibility determinants between nations}

According to the model, this part involves ten dimensions as such

1.1 Collectivism-Individualism Orientation: Hofstede considers culture to be a national-level phenomenon which can be utilized to explain people's different cognitions and behaviors among different nations. He proposed ranking countries on an individualismcollectivism continuum and then grouped countries in terms of similar and dissimilar cultures. Individualism stands for a society in which the ties between individuals are loose, collectivism stands for a society in which people from birth onwards are integrated into strong, cohesive in-groups, which throughout people's lifetime continue to protect them in exchange for unquestioning loyalty. (Venaik Sunil,Brewer Paul,2016). Gudykunst et al., reported that collectivists draw sharper distinctions between in-groups and out-groups than do members of individualist cultures. These distinctions were found to be related to differential patterns of communication. Collectivists tended to engage more extremely in intimate or non-intimate relations than individualists, who tended to communicate more consistently across groups. (Luoa Chuan et al,2016) Singelis et al. developed a theoretical distinction between vertical and horizontal forms of individualism/collectivism. Vertical individualism refers to valuing not only independence from one's groups, but also competitive distinction. Horizontal individualists see themselves as unique, but not necessarily better than other people. Vertical collectivists consider hierarchy an important part of society and either submit to others or 
dominate in their group. Horizontal collectivists try to submerge in the group, but do not see themselves as either subordinate or superordinate to others in the group. (Lee Yih-Teen et al, 2010) This distinction helps explaining one of the challenges of communicating across cultures: People within different cultures may not fit the overall cultural profile completely. Communicators from collectivist cultures place more emphasis on high context communication and attribute meaning to both the context and the receiver's orientation, which can be confusing to those in lower context individualistic cultures. In collectivistic cultures, message content is often embedded in the context of the communication. Thus, the receiver needs contextual cues to interpret the message properly and continually looks for cues in communication.(Leonard Karen Moustapha et al,2009) Differences across cultures suggest social influence varies because of the culture specific manifestation of the interaction effect. For example, Japanese tend to seek credibility based on caution with concern for a regulating some social image. Spanish tends to solicit credibility based on social recognition, a potential explanation of the interpersonal assertiveness found in Spanish culture. The American tends to solicit credibility more based on the interdependence found as a result of social group membership. The use of credibility, then, greatly depends on the audience's evaluation of the individual's responsibility to cautiously monitor individualistic with collectivistic, and independent with interdependent cultural values. (Dilbeck,Keith E.,2014,p27) People with different individual collective orientation values will utilize different cultural antecedent factors to evaluate the credibility of the received information during the communication process, due to the different impact mechanism of different factors. This dimension deserves to be put first in the model since it has been recognized as the most significant dimension to explain differences across cultures.

1.2 Power distance: Hofstede's work on power distance is relevant when discussing media use and credibility in various cultural contexts. High-power-distance cultures are likely to communicate using different media than in lower-power distance cultures. In high-powerdistance cultures, subordinates expect a clear distinction between themselves and their superiors, and the communication preferences are likely to reflect it.( Lee, Yih-teen, and al.,2010) Huang et al. 
found power distance had a great effect on whether email was an acceptable communication, because in high-power distance cultures, email did not satisfy the requirements for symbols and cues showing status and respect. In low-power-distance cultures, however, the information was all that was required, so the lack of symbols and cues was not considered a negative effect on its use. For example, People in Asian cultures tend to email their U.S. counterparts with copies to everyone above them in the hierarchy. This has led to significant misunderstandings and confusions between the two groups, as those in the U.S. culture tend to email their superiors only in specific instances, not in every email. (Leonard Karen Moustapha,2009, p861)

1.3 Nation-level: We can also differentiate culture and its communication patterns according to the nation-level. it means enable one to explore the cultural contexts in which varying amounts of agreement and disagreement are found. An extremity culture would be most likely be one in which strong loyalties to favored viewpoints are expressed within subcultural groups and strong antipathies are expressed toward other groups that are either within one's nation or outside it. In contrast, a consensus culture would be characterized by expressions of harmony and uniformity of opinions. In extremity cultures communication, would be more focused on in-group members than in dissent cultures. In moderate cultures, communication would likely be more indirect than in consensus cultures. In both extremity and moderate cultures, communication could be expected to vary between targets more than in consensus and dissent cultures.( Smith Peter B, 2011,p217)

1.4 Uncertainty avoidance: In high uncertainty avoidance countries, society places great weight on consensus and is intolerant to change. Low uncertainty avoidance countries have more tolerance for change and deviations from the norm, as well as less need for formal rules of conduct. ( Wood, Rahnl,A.1996, p220) People with a low level of uncertainty-avoidance tend to have more confidence in their ability to control the effect of media on themselves than those with a high level of uncertainty-avoidance. Yamaguchi et al. argued that Japanese with a high level of uncertainty-avoidance are less optimistic about their personal ability than about their collective ability and thus tend to favor collective control. Conversely, American with low uncertainty- 
avoidance are more optimistic about their personal ability than about their collective ability and are in favor of personal control. (Hong Seong Choul,2015) Thus, uncertainty-avoidance may be a good predictor of media content credibility.

1.5 Political regime: It determines media trust and effects. Cultural products play distinctive roles to maintain democratic values. New media can create a marketplace for ideas and a tool for creating an enlightened citizenry making them one of the most important avenues through which public opinion is shaped (Xia Ying,2016). Studies confirm the role of political regime in shaping media credibility and create image about media environment. A study found that the general attitude of American towards news stories is more positive than the attitude of Chinese, because American believe that the First Amendment guarantees the right to publish freely and that media are generally independent from the government and their journalistic professionalism is strongly developed. On the other hand, the totalitarian political regime in China has made the news media a tool of propaganda and censored their content. (Pjesivac, Ivanka, Rui, Rachel,2014,p655) Research confirm that in a culture with large power distance, there is stronger adherence to authoritarian norms as well as greater dependence on and acceptance of authority.(Wasti S.Arzu et al, 2007,p479) Political studies confirm the positive importance of new social media and the lack of importance of traditional mass media because of the relative capacity of the state to control the editing and distribution channels of these respective media.(Hassan Mazen et al.,2015) Differences in political contexts made credibility vary across cultures, for example, U.S people use to trust more official sources than a citizen or alternative sources, which contradict with people living in underdeveloped countries, where media skepticism prevail, and official have a very negative image because of their dictatorship behavior and corruption. Public opinion in authoritarian regimes perceives media credibility in a different way in comparison with a democratic country. For example, the role played by new media in so-called Arab spring countries, reflects a high dependency and credibility in these means comparing with western countries, where it doesn't have the same credibility(Kim Daekyung, Johnson Thomas J, 2009) Regarding media credibility 
generally, there is a big difference between democratic and nondemocratic countries. For example, Chinese believe that their government's censorship of a medium lends greater credibility to that medium. This view is consistent with the philosophy of Chinese leadership which maintains that it is the government's paternalistic responsibility to serve as a watchdog to ensure that media information is accurate and serves the public's best interest, which counter Western democratic models viewing the media as the watchdogs over the government.(He Fang,2003)

1.6 Technology: Not only is journalism's subject matter globalized, media audiences are also dispersed across the globe because of the globalization of media technologies. The society to which journalists now should be accountable is therefore not as easily defined as in the past, and media institutions now are dispersed across the globe and linked with multinational corporations. While these developments have focused the attention on the need for a globalized media practices, ethics and credibility, they have also exerted pressure on the traditionally dominant view of media credibility in the West, rooted in liberalism. (Wasserman Herman,2004) Morley and Robins speak of the difficulty of defining cultural identity in an era of postmodern geography where spaces are defined increasingly by electronic connectedness rather than physical proximity. The ready availability of transnational media, information and communications enhances such exposure to cultural globalization especially by the younger generation. (Thomas AmosOwen,2001) As tradition loses its hold and daily life becomes reconstituted in terms of 'the dialectical interplay of the local and the global', individuals are increasingly forced to negotiate lifestyle choices among a diversity of options, and this allows greater control over whether, when and how to assume a given social identity.(Grixti Joe,2006) Problems arise when people perceive their cultural inheritance as limiting or as lacking the 'freedom' which they assume to be more widely accessible elsewhere.(Xia Ying,2016)

1.7 Media ownership and regulations: Media faces a lot of internal and external challenges, which are reflected in media credibility. Media systems determine how people use media and how can they trust it. Political regime and media ownership influence media and journalists work in searching for independence and serving public 
opinion. Journalistic authority is a cultural construct through which journalists attend to their own legitimacy, credibility, moral purpose and ability to serve the public interest. (Jackson Richard Paul,2005) In media policy, economic and cultural objectives are often seen competing and within cultural diversity media policy, the pull between mission and market is central. (Horsti Karina, Hulten Gunilla,2011)

Journalistic practice is embedded within a structure that, in many ways, negatively impacts news reporting. Against the one-to-many, objective model underpinning traditional news outlets' claims to journalistic authority, competing forms suggested a blurring of the line between producers and consumers, increased accessibility and interactivity, and a move away from objectivity as a foundational emphasis. (Carlson Matt,2007) Early cross media credibility research found that online media tended to be perceived as more credible than their traditional counterparts. An online survey of politically interested web users found that online newspapers were considered more credible than their print counterparts. (Espina Camila,2013) The elite news outlets all struggled to maintain their relevancy against a changing media environment producing significant reductions in audiences.(Salmona Michelle et al.,2013) Journalists, also, face internal constraints concerning their need to demonstrate their autonomy from sources. The use of unnamed sources as a practice situated within the watchdog role of the news made journalists appeared beholden to their sources, which damaging journalism by problematizing journalism's stated norms, and news outlets become less credible to audiences when their practices were veiled.(Carlson Matt,2007,p282) Declining credibility concerns over credibility placed journalism in a contested cultural position. The judgment of one medium credibility over another may convey many cues concerning cultural context. For example, messages in written form may take priority over phone or face-to-face messages, for communicating "official"; however, in other culture, email may be the media of choice. (Leonard, Karen Moustapha et al.,2009,p853)

1.8 Legal System and constraints on news: Journalists advocate for increasing their legal protections, and worked to retain control in defining the norms that inform journalistic authority. This included explaining away controversies either as isolated incidents of bad 
practice or due to negative constraints outside the control of the newsroom. ( Carlson Matt,2007,p270) The type of legal system may influence directly or indirectly not only the conduct of media, but also the role the media plays.(Wood Rahnl A.,1996) This perspective on the media's role is linked to a prevailing human rights discourse, constitutional guarantees and the assumption of a free market environment in which the media undertake to act responsibly in the public interest, free from governmental intervention.(Wasserman Herman,2004,p76) Journalists portrayed any kind of intervention as interfering with journalistic autonomy, and therefore threatening journalism's democratic role.(Flyn Jeffery Regan,2006) However, considerations of legal constraints also raised questions around whether journalism deserved this special status. Journalists argued for increased rights on the grounds their work justified such provisions through its public benefit. Others argued that journalists didn't deserve these rights, calling attention to journalistic missteps and deviation. The legal system determines the degree of media freedom which in turn reflect the degree of media credibility and trust.

1.9 Religion: In traditional cultures religion is very important; people idealize large families, they also have high levels of national pride, favor more respect for authority, reject divorce, abortion and suicide. Societies with secular-rational values have the opposite preferences on all these topics.(Malekil Ammar,de Jong Martin,2014) This may cause misunderstandings and need more accurate instrument to be applied carefully when dealing in cross culture studies. An example is an instrument measuring spirituality, which was developed in the West where Christianity is the common religious foundation. God references in the instrument represent the notion of God typical of Western religion. However, for a cultural group such as Chinese or Japanese, God refers to Buddha, gods, and ancestor spirits. In Islam, the oneness of God is Allah based on Quran, the holy book of Islam.(Kao Hsueh-Fen S. et al.,2004) Another example can be seen in Latinos, which believe sick people are haunted by empacho (evil spirit) and therefore need to see a curandero (healer) instead of visiting a medical doctor. this may be interpreted to mean Latinos are unsophisticated in their knowledge of health systems. Misconceptions about the motivation and behavior of cultural groups blind health 
professionals to problems of poverty and racism.( Kao Hsueh-Fen S. et al.,2004,p273) So it is important to consider religious principles when measuring media credibility in cross culture studies.

1.10 Economic status: Adorno and Horkheimer criticized the cultural industry, for mass-producing cultural products in the service of capitalist economies. They saw the media both as the means to subjugate the masses as well as the undoing of civilization as they idealized it rather belatedly in the industrial age. By inducing passivity and addiction in audiences, thus making them amenable to domination by the political and economic elite in society, the capitalist system of mass production and consumption sustained itself.(Athique Adrian,2008) Studies confirm that the associations between media trust and economic development and democracy became insignificant when controlling for post materialism implies that people's trust in the media is lower in prosperous and democratic societies, because the post materialistic culture in such societies makes them more critical of media institutions.(Tsafi Yariv, Ariely Gal,2013) However differences in media credibility exist due to economic development and the gap between rich and poor countries, which need more examination in media credibility research.

1.11 Timing (Routine vs. Crisis period): The reporting bias becomes more salient in the minds of publics in times of crisis because media responses to a negative event increase public scrutiny(Park Hyojung, Cameron Glen T.,2014) In crisis and disaster situations the accuracy, credibility and timeliness of media information depend on relationships between journalists and emergency managers. In the chaos of an unfolding disaster, this relationship relies heavily on trust (Mclean Hamish,Power Mary R.,2014)

\section{The Cultural context credibility determinants within cultures}

Although Hofstede indicates culture is a national-level phenomenon, some studies believe it also can be applied to individual level, since individuals, even in a single nation, often espouse cultural values to different degrees. Findings from recent studies show that even greater variation in individual differences exists within cultures than across cultures.(Klafehn Jennifer et al.,2013) It assumes that although culture 
is shared within a group, individuals who belong to that group differ in the extent to which they value and express particular cultural norms.(Kreuter Matthew W, Haughton Lorna T.,2006) To solicit credible identity attributions, people communicate in ways that grant cultural membership to experience a sense of belonging. Cultural norms provide guidelines from which to regulate the behavior of members of various cultures and therefore the use of credibility to stimulate the intended meaning in an audience. (Dilbeck,Keith, E.2014,p34) Scholars affiliated with British cultural studies suggested that divergent political and cultural experiences lead people to participate in different arenas of political and social discourse. These alternative discursive arenas both build upon and contribute to contrasting group outlooks on societal affairs which then lead to varying interpretations of mass media.(Doorkin Mark Allen,1987) Spencer-Oatey explains that in intercultural communication, culture is usually associated with social groups, which can be differently constituted depending on the criteria used; sex, age, religion, nationality, occupation, and language.( Salmona Michelle,2013,p319)

The proposed model involves five dimensions in this section as such:

2.1 Acculturation: According to the literature different elements must be taken in consideration when studying society, first and most important the acculturation process. Some cultures are more accepting of different groups and welcome diversity, while others expect the ethnic minority groups to assimilate to the new culture.(Bhagwat Aditya Avinash,2001) Sometimes people tend to diverge from a new culture and keep a strong affiliation for their original cultural values.(Moon Seung-Jun,2004) Krefting suggests that culture must be considered individual culture and that each person's contact with and interpretation of the culture is unique".(Beune Karlijn et al.,2010) According to previous acculturation studies, interaction with a host country encourages identification by members of immigrant groups. In turn, media credibility research contends that increased levels of source-receiver identification result in higher credibility assessments. In a world of increasingly global economies and social media, people across opposite ends of the globe are more and more subject to common influences. Thus, cross-cultural similarities and differences 
are as salient within a nation as they are across nations. Cultural groups should therefore be identified on the basis of similarities and differences between individuals on characteristics of interest to the researcher irrespective of their nationality or physical location.(Venaik Sunil, Brewer Paul, 2016)

2.2 Group membership: Group-membership affects opinion formation and change, as well as perceived media credibility. In individualist cultures, people tend to care more about 'with whom' they want to establish a tie, and go through a more selective process of evaluating fit in terms of value or personality similarity. They pay more attention to deep-level similarities, which can help to cooperate more effectively with colleagues. On the other hand, in collectivist societies people tend to build relationships based on a broader range of commonalities. Thus, the effect of surface-level similarity may be relatively more pronounced. Farh et al. found that relational demography, which concerns surface level similarities between an individual and others regarding factors such as age, gender, race, and occupation is important for subordinates trusting their supervisors in Taiwan and China. Similarities based on coming from the same village, bearing the same family names or attending the same schools can more easily create a sense of belonging and hence facilitate social capital building. Likewise, Chen et al. found that group membership carries stronger psychological attachment for collectivists than for individualists. Evidence shows that people in individualist cultures display a higher propensity to trust and a lower propensity to distrust than those from collectivist cultures. (Lee Yih-teen et al.,2010,p166) Accounting for social and cultural context alongside classical variables associated with social position is necessary when attempting to explain media consumption habits and credibility. Individuals within their society are guided by a group of behavioral rules and norms that are inherent within their specific society. Culture tells us not only how to behave but also how to interpret the behavior of others and how to communicate with them. Therefore, culture influences, not only, interpersonal and group relationships (Leonard Karen Moustapha et al.,2009,p859), but communication patterns, behaviors and media credibility too. Cultural theories suggest that communication effectiveness is, in part, socially determined. 
Communication patterns reflect cultural heritage. So, creating a framework for understanding media credibility among different social structures through the lens of their culture is not sufficient. We must analyze social positions, relations, histories and communicative practices allows for a comprehensive outlook on cultural reproductions that defines and gives media spaces their endemic character.(Arora Payal,2012,p601)

2.3 Social classes: Previous studies have shown that social class and culture capital play a decisive role in media choice and credibility. National culture preference is not uniform across social classes. Lower and middle classes reflect a stronger attachment to local culture, while the elites demonstrate cosmopolitan interests when it comes to media content. People with higher socioeconomic status are more likely to consume print media than broadcast media, and have a higher knowledge of public affairs. As for cultural capital, Straubhaar stresses the relationship between social class position, and experiences as well as interactions with foreign cultures and media.(Espina Camila,2013,p52)

2.4 Cultural proximity: Perceived cultural proximity is based on characteristics like shared language, clothes, religion and lifestyle. It depends largely on what Straubhaar identifies as cultural capital, understood as the sources of knowledge that inform people's media choices. McCroskey, Richmond, and Daly developed a sourcereceiver similarity scale in interpersonal communication to address to what extent the receiver perceived the source as similar to themselves in terms of attitude, background, value and appearance. (Xu Xiaowen,2014) Studies suggest a relationship between cultural proximity and credibility assessments, confirming audiences' predilection for media content that is culturally similar.(Belhoste Nathalie,Monin Philippe,2013)

2.5 Gender egalitarianism: House and Javidan define gender egalitarianism as 'the degree to which a society minimizes gender role differences while promoting gender equality'. Erez and Early interpret it as differences between gender roles, with fewer differences in a feminine culture and more differences in a masculine culture.(Athique Adrian,2008) Masculinity is a problematical dimension in that it combines different cultural features. This dimension of culture might 
be drastically changed as a result of modernization, but we can still identify some modern societies with a strong role division between genders.(Maleki Ammar,de Jong Martin,2014,p121) Sex differences in technology usage was attributable to a number of factors, such as cultures that encourage males' technology use disproportionately over that by females. (Flanagin Andrew J, Metzger Miriam J.,2003) The sex of the communicator has also been related to the perceived credibility, influenced by cultural context. Studies confirm that males were perceived more credible than females during a persuasive message. Whittaker and Meade found that when a political message was oral, males were rated as more credible than females in Brazil, India, and Hong Kong. Richmond and McCroskey survey revealed that males were preferred over females as opinion leaders on the topic of political events, However, females were chosen as opinion leaders on the topics of Fashion and movies (Wood Richard Nelson,1978).

2.6 Age: Although young people everywhere increasingly share similar tastes in styles of dress and entertainment; there are still significant regional, ethnic and cultural differences in the ways they use and appropriate the media technologies at their disposal.(Grixti Joe,2006,p107) Youths' consumption-related identity performances are context dependent, there are sets of social and cultural expectations that are maintained within the various social groups that young people move between, and youth perform a range of identities depending on the context they inhabit. (Millington Brad,Wilson Brian,2010) Research indicates that young web users consider the internet more credible than the traditional media. Flanagin and Metzger found that college students, compared to the general population, rate information online as more credible.(Flanagin Andrew J, Metzger Miriam J.,2000) Similarly, Kang found that young people generally hold positive attitudes toward online news.(Kang,C.Y,2009)

\section{Discussion and directions for future research}

The purpose of this article was to examine the role of culture in credibility assessment. It suggests that credibility perceptions are influenced by cultural dimensions between the different countries and within cultures and it proposes a multidimensional model which explain variables in more details and clarify its relation to media 
credibility. The previous quantitative literature identified culture as a crucial element in media credibility, but mainly focused on the communication components. I sought to contribute to this literature by providing a model of cultural and communication components that influence media credibility across and within cultures. My theoretical framework reviewed the existing research on communication and culture and developed a model imposing essential factors. The model offers insights into the credibility dynamics by linking culture, social capital and media. Although I was unable to examine these factors directly in this paper, I suggest that further investigation of processes in future research is warranted. I believe that the questions addressed in this article are of theoretical relevance. For scholars, a useful next step would entail empirically testing the model. Conceptually, it is also possible to further refine the model. For example, other contextual factors may also moderate the relationships in the model. Since it is beyond the scope of this paper, I would encourage future research to explore them in more detail. It is not possible to discuss all the cultural variations identified by all the research; therefore, I have chosen these dimensions, which I believe are the most salient to the larger issue of media credibility processes. The main implication of the current article suggests that additional influential factors might emerge when exploring credibility perceptions from a broader scope or cross-national perspective. These factors are inherently intertwined to the environmental context: political, economic, legal, economic, media systems ... of the nations in question.

The present article suffers from some methodological limitations, resulting from excessive reliance on secondary data and purposefully chosen examples. Therefore, more empirical research would be useful. Generating a better understanding of the different forms of media credibility across different kinds of groups and across different countries would be useful to academics and professionals alike. Although the proposed model identifies multiple variables involved in credibility cultural dimensions, I realize it is limited. Also, I ignore the quantitative contributions of these variables; however, this was beyond the scope of this article. The strength of my current approach is that by specifying dimensions of culture on media credibility within and across cultures, future research will be better able to integrate 
other variables that are directly related to it. Another limitation is the lack of development of the interactions between cultural variations. I have been concerned mainly with the different cultural dimensions on perceptions of media credibility, I believe that further work on such interactions would be valuable. 


\section{References}

2. Arora Payal(2012), Typology of Web 2.0 spheres: Understanding the cultural dimensions of social media spaces, Current Sociology, vol 60(5), Pp 599- 618, Sage publications, DOI: $10.1177 / 0011392112440439$.

3. Athique Adrian(2008|), Media audiences, ethnographic practice and the notion of a cultural field, Cultural Studies, Vol 11(1),Pp 25-41; Sage Publications , DOI: 10.1177/1367549407084962

4. Bakaki Zorzeta, Böhmelt Tobias, Bove Vincenzo (2015), Barriers to Coordination? Examining the Impact of Culture on International Mediation Occurrence and Effectiveness, Political Studies, Political studies association, DOI: 10.1111/1467-9248.12199

5. Belhoste Nathalie, Monin, Philippe(2013), Constructing differences in a cross cultural context: National distance, social differentiation or functional distinction, Human Relations,vol66(12), Pp 15291561, Sage publications DOI: 10.1177/0018726713484943

6. Beune Karlijn, Giebels Ellen, Taylor, Paul J.(2010), Patterns of interaction in police interviews: The Role of cultural dependency, Criminal Justice and Behavior, Vol. 37(8) Pp:904-925, International Association for Correctional and Forensic Psychology, DOI: 10.1177/0093854810369623

7. Bhagwat, Aditya Avinash"(2001), Cultural variables salient to the social influence model of counseling: The case of Asian Americans, $\mathrm{PhD}$ thesis, Ohio State University.

8. Carlson,Matt(2007), On the condition of anonymity: Unnamed sourced and journalistic authority, $\mathrm{PhD}$ thesis, University of Pennsylvania.

9. Demetrovics, Zsolt(2012), Adolescent Behavior and Health in Cross-Cultural Context, Journal of Early Adolescence, vol 32(1), Pp 14-19, Sage publications, DOI: 10.1177/0272431611432713.

10. Dilbeck, Keith E.(2014), Vicarious and source credibility: A cross cultural explanation, PhD thesis, The university of WisconsinMilwaukee.

11. Dworkin, Mark Allen(1987), Making sense with Television News: Situation, Context, and Psychology of the Audience Experience, $\mathrm{PhD}$ thesis, University of Washington.

12. Espina, Camila(2013), Perceived cultural proximity and perceived news source credibility in Puerto Rico, Master of Arts, Syracuse University.

13. Flanagin, Andrew J., Metzger, Miriam J.(2003), The perceived credibility of personal Web page information as influenced by the 
sex of the source, Computers in Human Behavior,vol.19,Pp: 683701.

14. Flanagin, A. J., \& Metzger, M. J. (2000). Perception of Internet information credibility. Journalism \& Mass Communication Quarterly, 77,Pp: 515-540,Sage publications.

15. Flynn, Jeffrey Regan(2006), Human rights and cultural diversity: Rawls, Taylor, Habermas, PhD thesis, Northwestern university.

16. Grixti Joe(2006), Symbiotic transformations: youth, global media and indigenous culture in Malta, Media, Culture \& Society, Vol. 28(1), Pp105-122,Sage publications, DOI: $10.1177 / 0163443706059295$.

17. Hassan Mazen,Elisabeth Kendall,Stephen Whitefield(2015), Media, Cultural Consumption and Support for Democracy in PostRevolutionary Egypt, Political Studies, DOI: 10.1111/14679248.12203

18. He,Fang(2003), Chinese college students' perceptions of media credibility and free speech in the internet age, master, California state university.

19. Hong, Seong Choul(2015), Do cultural values matter? A crosscultural study of the Third-Person effect and support for the regulation of violent video games, Journal of Cross-Cultural Psychology, Vol. 46(7), Pp964- 976, DOI: $10.1177 / 0022022115588950$

20. Horsti, Karina, Gunilla Hultén(2011), Directing diversity: Managing cultural diversity media policies in Finnish and Swedish public service broadcasting, International journal of cultural studies, Vol14(2),Pp: 209-227, DOI: 10.1177/1367877910382180

21. Jackson, Richard Paul(2005), Searching for a Voice of Authority in Newspaper Writing, PhD thesis, University of Washington.

22. Jackson Timothy A., Meyer John P., and Xiao-Hua Wang(2013), Leadership, Commitment, and Culture: A meta-analysis, Journal of Leadership \& Organizational Studies, vol 20(1), Pp: 84-106, Sage publications , DOI: 10.1177/1548051812466919

23. Johnson Thomas j. and Shahira Fahmy(2008), The CNN of the Arab world or a shill for terrorists? How support for press freedom and political ideology predicts credibility of Al-Jazeera among its audience, The international communication gazette, vol.70(5),Pp: 338-360, Sage publications. 
24. Kang, C. Y.(2009), Communication technologies: Diffusion of online news use and credibility among young web users in the information age, master's thesis, University of Nevada-Las Vegas.

25. Kao, Hsueh-Fen S., RN Min -Tao Hsu, Lauren Clark(2004), Conceptualizing and critiquing culture in health research, Journal of Transcultural Nursing,Vol.15(4),Pp269-277,Sage publications.

26. Kim Daekyung and Thomas J. Johnson(2009), A shift in media credibility: Comparing internet and traditional news sources in South Korea, The international communication gazette, vol71(4),Pp283-302, Sage publications .

27. Klafehn, Jennifer, Chenchen Li, and Chi-yue Chiu(2013), To Know or Not to Know, Is That the Question? Exploring the role and assessment of metacognition in cross-cultural contexts, Journal of Cross-Cultural Psychology, 44(6), Pp 963- 991, Sage publications, DOI: $10.1177 / 0022022113492893$.

28. Kreuter Matthew W., Haughton, Lorna T.(2006), Integrating Culture Into Health Information for African American Women, American Behavioral Scientist, Vol49 ( 6),Pp 794-811 Sage publications.

29. Lathrop,Christopher(1984), The effects of context on receiverperceived dimensions of credibility using subject-generated scales, master, Wyoming university.

30. Lee, Yih-teen, Reiche, Sebastian B. and Song Dongmei (2010), How do newcomers fit in? The dynamics between person-environment fit and social capital across cultures, International Journal of Cross Cultural Management, vol 10(2), sage publications, DOI: $10.1177 / 1470595810370911$

31. Liu, Zhengjia, Berkowitz, Dan(2014), "Where is our Steve Jobs?” A case study of consumerism and neo-liberal media in China, Journalism, Vol.15(8),Pp:1006-1022, Sage publications, DOI: 10.1177/1464884913508608

32. Leonard, Karen Moustafa, Scotter James R. Van, and Pakdil Fatma (2009), Culture and Communication: Cultural variations and media effectiveness,Administration\&Society,vol41(7),Pp850-877,Sage publications, DOI:10.1177/0095399709344054

33. Lowe, Susana Ming(1997), Impact of Individualist and Collectivist Approaches to Career Counseling with Asian Americans on Perceptions of Counselor Cross-Cultural Competence and Credibility, $\mathrm{PhD}$ thesis, University of California.

34. Luoa Chuan, Jing Wua,, Yani Shib, Yun Xu(2016), The effects of individualism collectivism cultural orientation on e-WOM 
information, International Journal of Information Management, vol 34,Pp 446-456,at: www.elsevier.com

35. Maleki, Ammar and Martin de Jong(2014), A Proposal for Clustering the Dimensions of National Culture, Cross-Cultural Research, Vol. 48(2), Pp107-143, Sage publications, DOI: 10.1177/1069397113510268

36. Mclean Hamish,Power Mary R.(2014), When minutes count: Tension and trust in the relationship between emergency managers and the media, Journalism, vol. 15(3),Pp 307- 325, Sage publications.

37. Millington, Brad and Wilson, Brian(2010), Context Masculinities: Media Consumption, Physical Education, and Youth Identities, American Behavioral Scientist, vol53(11),Pp:1669-1688, Sage Publications, DOI: 10.1177/000276421036809

38. Moon, Seung-jun(2004), Immigration, Acculturation, and mass media effects: Cultural Values and Evaluations of Caucasian and Asian advertising models, $\mathrm{PhD}$ thesis, University of WisconsinMadison.

39. Park Hyojung and Glen Cameron, T.(2014), Keeping it real: Exploring the roles of conversational human voice and source credibility in crisis communication via blogs, Journalism \& mass communication quarterly, vol. 91(3),Pp 487-507, Sage publications.

40. Pjesivac, Ivanka, Rui, Rachel(2014), Anonymous sources hurt credibility of news stories across cultures: A comparative experiment in America and China, the International Communication Gazette, Vol. 76(8),Pp: 641-660,Sage publications.

41. Salmona Michelle,James Melton,Robert Miller(2013), Online social networking across cultures: An Exploration of divergent and common practices, Technical writing and communication, Vol. 43(3), Pp: 317-331, Baywood Publishing Co., Inc.,.

42. Smith,Peter B.(2011), Communication Styles as Dimensions of National Culture, Journal of Cross-Cultural Psychology, vol42(2),Pp216-233, Sage publications, DOI:10.1177/0022022110396866.

43. Thomas, Amos Owen(2001), Global media corporations and the nation state: Balancing politico-economic and socio-cultural globalization, Global business review, vol 2(1), Pp:71-82,Sage publications. 
44. Tsfati Yariv and Gal Ariely(2013), Individual and contextual correlates of trust in media across 44 countries, Communication Research, vol. 41(6),Pp: 760-782, Sage publications.

45. Venaik, Sunil and Paul Brewer(2016), National culture dimensions: The perpetuation of cultural ignorance, Management Learning, Pp127,Sage publications. DOI: 10.1177/1350507616629356

46. Wasserman Herman(2004), Globalized values and postcolonial responses: South African Perspectives on Normative Media Ethics, The International Communication Gazette,vol68(1),Sage publications, DOI: 10.1177/1748048506060116.

47. Wasti, S. Arzu, Hwee Hoon Tan, Holly H. Brower, Çetin Önder(2007), Cross-cultural measurement of supervisor trustworthiness: An assessment of measurement invariance across three cultures, The Leadership Quarterly, vol 18,Pp 477-489.

48. Wood, Rahnl A.(1996), Global Audit Characteristics Across Cultures and Environments: An Empirical Examination, Journal of International Accounting, Auditing \& Taxation, vol. 5(2),Pp:215229

49. Wood, Richard Nelson(1987), The effects of sex and age on the perceived credibility of a simulated local television newscast, $\mathrm{PhD}$ thesis, The university of Arizona.

50. Xia Ying(2016), Collective action frame and cultural context: A study of the anti-express-rail-link movement in Hong Kong, Chinese Journal of Sociology, Vol. 2(2), Pp300-323,DOI: $10.1177 / 2057150 X 16633579$

51. Xu, Xiaowen(2014), The influence of the message source's national identity on Chinese international students' attitudes, Master of Arts, Michigan State University. 